\title{
The contribution of asset management to climate change policies
}

\author{
B. Bürgenmeier \\ Centre of Human Ecology and Environmental Sciences, \\ University of Geneva, Switzerland
}

\begin{abstract}
This paper deals with the three usual economic approaches to environmental protection, namely efficient markets, environmental economics and ecological economics. It focuses on a forth approach, which concerns the operational level of a business. This level is illustrated by an increasing number of criteria for global reporting, namely Social Accountability, ISO-norms etc, from the World Business Council for Sustainable Development. However, no commonly accepted standards exist. This paper shows what contributions "green" asset management makes to climate change policies.
\end{abstract}

Keywords: climate change, asset management, environmental economics, policy of environmental protection.

\section{Introduction}

Environmental protection in economics is simultaneously addressed by three different and somewhat controversial approaches.

The first approach analyses the change in relative prices over time in a pure market setting. Relative price changes (e.g. for energy of fossil origin) should express increased scarcity and induce technical progress and change in consumption patterns. If these changes cannot be observed, the market is not efficient. The consequent policy recommendation would be to strengthen competition and to reduce obstacles to the smooth functioning of markets.

The second approach brings the first one a step further as it is based on the concept of market failure. The environment is analysed as an externality to the market and can be understood either as a public good or as any other economic good which lacks a clear definition of property rights. The current policy 
recommendation concludes that the promotion of economic instruments is warranted. It can theoretically be shown that these instruments are protecting the environment at a lower cost than control and command instruments (Tietenberg [11]). This second approach is clearly in the field of environmental economics.

The third approach is developed in the field of ecological economics (Dore and Mount [2]). It introduces a change in perspective. The economy is external to the environment and has to be internalised into models of physical constraints to human activity, which cannot only be understood in terms of both economic and social dimensions. This paper argues that there is no model in sight that takes into account the social dimension in a satisfactory way. This dimension is probably the most misunderstood aspect of environmental issues. It raises fundamental questions about the aim and scope of economics. These questions are at the origin of the first reason why equity questions cannot be solved by models of growth (Constanza [1]).

Environmental issues have to be understood as a supplementary difficulty, added to the much older one of determining the "just price" which is tackled together with the "social question". The cumulative effects of the environmental and social consequences of human activities also extend the traditional approach of distributional justice to procedural and intergenerational justice with profound ethical implications (Hausman and McPherson [5]).

Increasing concern with social and environmental responsibility in business has led to the promotion of specially designed portfolios in asset management. This paper addresses this fact through five parts. The first introductory part recalls the ethical principles of the market in order to show that economic practices have been understood to be ethically sound, long before this trend actually occurred. Therefore, the second part shows that old problems have led to new questions and that the market economy stresses a never solved trade-off between efficiency and equity. The third part discusses the ethics of sustainable development and analyses this trade-off in relation to environmental protection. The fourth part is concerned with asset management, presents the main criteria and discusses the performance of sustainable portfolios. The fifth and final part concludes the reasons, explaining the trend towards social and environmental standards in asset management.

\section{Welfare economics}

That the functioning of markets is based on ethical principles is theoretically well grounded, but is sometimes forgotten in current business practices. These principles are well-known. Contracts have to be respected, competition has to be the binding rule of business, where transparency of all disposable information is granted and finally market access has to be unlimited for both businesses and consumers. Relative price changes lead to innovation through investment in research and development and to changes in consumer behaviour. The objective is profit maximisation on the level of the business and growth on the level of the nation. 
Relative price changes have distributional consequences widely discussed in welfare theory throughout the history of economic thought. According to Amartya Sen, this "social question" stresses the fact that relative price changes exclude consumers with the lowest income and is intimately linked to the functioning of markets (Sen [8]).

Any attempt to analyse "economics as physics" is confronted with the normative aspects of the distribution of income and wealth. Standard economic approaches are bypassing the issue in focussing on output. The conclusion of welfare theory is to accept the normative content of distributional issues, and to show that it can be solved by economic growth (Feldmann [3]). In reducing sustainable development to sustainable growth in order to take into account equity issues, this strategy exclusively counts on modelling technical progress within the economic dimension.

Equity is only one aspect of the social dimension of sustainable development, which cannot be treated separately. It invites an understanding of complexity, instead of reducing it to models of simple causality. Equity is also interrelated with the economic and ecological dimension of sustainable development, while models of causality keep it separate. In focusing on ethics, the current discussion leaves out a long understood finding, namely that competition policy world wide is the best way of promoting ethical standards in business because it reduces all kinds of rents which are frequent in current economic practices. An international law of competition is lacking. The World Trade Organisation only reduces obstacles to free trade decided by States, but not of private businesses.

The fact that different aspects of equity have to be taken into account and several concepts of it co-exist makes it difficult for the business to clearly identify the extent of its responsibility. If only distributional equity is taken into account, it is also the most effectively addressed by economic growth. The specific characteristics of sustainable development are left out of the analysis.

One of the main findings of the 1987 report of the World Commission on Environment and Development [12] was the insight that there will no efficient policy for environmental protection if that policy did not also significantly reduce inequalities in income and wealth distribution in the world. This social dimension has not been studied systematically; most of the attention of the academic world has focused on the ecological and economic dimensions. Meanwhile, the business community has been confronted with an increasing separation of the real economy from finance, which is de-connected more and more from investment decisions for economic growth and not for financial performance.

\section{Historical perspective}

The origin of ethical investment goes back to the Great Depression in the thirties. Facing increasing unemployment, the trade-off between efficiency and equity appeared clearly. This historical reminder led to an increasing concern for public morality where the definition of ethical investment was determined by public health, arms and drugs. The recent trend for increased social responsibility of 
businesses only transforms this concern from a hidden agenda to a more transparently discussed issue. At the same time, public morality still condemned any treatment of risk and uncertainty during the nineteenth century as pure gambling. To bring such a treatment in the scope of economics was the task of insurance, which became a flourishing branch, and nowadays is more and more close to asset management and finance in general.

With the increasing conscience for environmental issues, ethical investment has finally been understood in relation to the concept of sustainable development including ethics in its social dimension. Table 1 lists the main aspects of this dimension and states the contextual framework of any modelling. The social dimension of sustainable development, like the concept of the market economy, is socially constructed. It is not so much the clear definition of this dimension which matters, but the image, the narrative content and the social symbols that are associated with it.

Table 1: $\quad$ Different aspects of the social dimension.

\begin{tabular}{|l|l|}
\hline 1 & $\begin{array}{l}\text { Social Institutions (Do institutions matter in human behaviour?) } \\
\text { International and national institutional reforms and new bodies } \\
\text { Legal framework (e.g. property rights) } \\
\text { Monetary versus non-monetary evaluation }\end{array}$ \\
\hline 2 & $\begin{array}{l}\text { Life Style Analysis } \\
\text { Consumption patterns (e.g. behavioural assumptions) } \\
\text { Social images of Nature and technology (e.g. linguistic) } \\
\text { Communication and Media }\end{array}$ \\
\hline 3 & $\begin{array}{l}\text { Social Cohesion } \\
\text { Aggregation problems } \\
\text { Government failures (intensity of preferences, Condorcet's paradox, } \\
\text { lack of voting incentives) }\end{array}$ \\
\hline 4 & $\begin{array}{l}\text { Equity } \\
\text { Normative content of the concept of equity } \\
\text { Different forms of equity }\end{array}$ \\
\hline
\end{tabular}

\subsection{Social institutions}

The first group of arguments concerns the place of social institutions in economic analysis. Neoclassical theory both overemphasises and underestimates the importance of social institutions. It overemphasises them in assuming that social institutions are the rock foundation on which the economic calculus takes place. It underestimates them in assuming that individual preferences are given reflecting individual choices where social habits and institutions do not count.

In reforming the financial market in the perspective of sustainable development, not only are international institutions such as the Kyoto Protocol introduced, but also a new legal framework for emission trading and new evaluation methods for sustainable asset management. 


\subsection{Behavioural assumptions}

Life Style Analysis can be approached in different ways. It is dominated by the theory of consumer choices based on cost-benefit analysis and the assumption of given preferences. Free rational choices are assumed in economic theory and there are as many behavioural assumptions as disciplines in the social and human sciences (e.g. Söderbaum [10]).

Different aspects of human behaviour are studied by different social sciences, but they can be divided into two main groups. The first one consists of consumer preferences when it comes to explaining why climate change policies have a more rhetorical than a practical support. The second one consists of social consumer habits but fails to clearly identify what is their origin. Human behaviour attributed to deep ecological concern can be expressed by lexicographical preferences, which are in contradiction to the assumption of transitivity underlying models of rational consumer behaviour (O'Connor and Spash [7]). There are attempts to clearly distinguish categories of behaviour of economic, ecological or social man, but these distinctions fail to answer the question of where the motivations for taking care of the environment come from.

\subsection{Community}

The third group of research in the field of the social dimension of sustainable development deals with the question of social cohesion. It offers a sociological perspective and a critique of economic approaches, which have to overcome an aggregate problem. If social welfare is just the sum of individual choices, where each knows best what is in his interest, it fails to grasp an important aspect, namely community building.

The fact that economic theory cannot link individual choice theory to social welfare has meant that some refer either to the representative individual which stands for all others, or to a social indifference curve without any link to individuals (Harsanyi [4]). This disconnection condemns any attempt to build models on microeconomic foundations in order to analyse social welfare functions and hence social equity issues. Those issues remain in the normative domain. Therefore, they are delegated to the political sciences in order to keep economic models consistent with the basic assumptions on which they are built.

\section{Ethics of sustainable development}

Ethics as a part of the social dimension of sustainable development combines the different findings of the above-mentioned groups. If natural resources are expressed as a source of welfare itself, the social image of Nature is used in national parks, created in the $19^{\text {th }}$ century by the conservationist movement in the United States. Equity questions are then expressed by a more procedural form of justice. In this perspective, it is no longer possible to treat equity in the form of distributional justice only. Finally, if the social image of the environment is 
expressed in terms of garbage, society focuses environmental issues on recycling, and this refers to inter-generational equity.

The environment, seen as factor of production, as a source of well being, or as garbage, expresses different perspectives and addresses equity in different ways. Therefore equity cannot be a single expression for normative issues. It has to be understood in different terms making it even more difficult for a particular business to take equity into account.

The term "equity" stands for different interpretations of justice and can be expressed in different ways. It mainly covers distributional, procedural and intergenerational justice.

\subsection{Distributional justice}

Distributional justice intervenes on at least three distinctive levels:

- The first level deals with the distribution of income and wealth among individuals. It is closely linked to economic models based on a micro, business and household oriented foundation. The relevant question is to know which among several possible Pareto optimal solutions is the one which best satisfies distributional outcomes. This question can only be answered on normative grounds.

- The second level situates distributional justice among different countries. It is usually analysed within the theoretical framework of international trade, which is built on micro-foundations as well as reaffirming the usual finding that "more is better than less". Distributional issues are the consequence of environmental policies on an international scale such as the ones foreseen by the Kyoto Protocol. If they are addressed by separating their normative content from the positive analysis carried out as a formalised model, then they are exposed to the same shortcomings to which distributional issues on the individual level are exposed.

- The third level of distributional justice concerns inter-generational equity in terms of distribution issues, which introduce a new ethical yardstick in human activity. This distributional issue is unprecedented and is considered by many as the key feature of the concept of sustainable development. It refers to a fundamental choice. Either, this inter-generational distribution is ignored and conventional economic models continue to be extended to climate change; or it is not ignored and those models fail to grasp the very nature of the concept of sustainable development. The old "social question" is also asked in respect of future generations, which significantly increases the normative part of any economic reasoning.

\subsection{Procedural justice}

This second aspect of equity treats the way in which procedural justice shapes the economic process. The gearing principles of procedural justice are precautionary as well as intra-and inter-generational ethics. This procedural justice can be found in different stages of production, in transport and other intermediate activities, as well as in consumption. We recall four of them: 
- At the first stage these principles intervene in the market of the factors of production. They are mainly used to justify energy and more generally all non-renewable natural resources saving programmes. They are also linked to the respect of social norms, which are set by ILO, but not always enforced (such as child work and minimum hygienic and health standards in resource extraction and pollution exposure).

- At the second stage, these principles design the social and ethical context in which a production function is set. Economic theory portrays such functions as a purely technological relationship between different factors of production. The technological part is expressed in models, the contextual one is not. We are confronted with two different kinds of approaches that cannot be put together in a unified and formalised framework.

- At the third stage which is defined by all intermediate activities between production and consumption, (such as merchants, financial intermediates, insurers and transporters), these principles set standards, which are often seen as obstacles to trade. The requirement to favour public transport systems instead of individual private vehicles is not only motivated by the internalisation of external effects, because it also has ideological implications. Public transport, for example, favours State intervention and relies more often on strategic planning procedures than on competitive markets.

- At the fourth stage, these principles are also shaping consumption. Herbert Simon has already insisted that rational consumer choices are bounded by asymmetric information (Simon [9]). We can now add that they are also bounded by precaution and ethics. Bounded rationality leads to cooperation and not so much to competition. This organisational perspective of consumer behaviour has lead to a theory of consumer behaviour, which analyses a household as a production unit. Though this theoretical extension of the classical consumer choice theory is based on preferences. This extension can be expressed by formal models and is also useful in order to take into account litter and waste; it does not fully include principles of procedural justice. Why should a consumer contribute to recycling his own waste if he pays taxes that are used for public garbage collection? The ethical incentive is the consumer's awareness to be part of a community, which is again an element that does not enter in formal models.

\subsection{Intergenerational justice}

Finally, this third aspect of equity is a particular form of procedural justice, which is extended to future generations. This extension introduces a radical change in perception and it is probably one of the major reasons why many scholars, mainly regrouped in ecological economics, are against the use of extended economic models applied to climate change without questioning the underlying methods of research. It is difficult to evaluate the long-term impact of research, which highlighted this radical change in perception (Martinez-Allier [6]). However, while new strands of thought are explored we can only promote pluralistic approaches coexisting and challenging formal modelling. 
These approaches also insist on the cultural determinants of intergenerational justice and link this aspect of equity to the demographic factor intervening in environmental issues. If children are seen as descendants of a cult and moreover play an important part in perpetuating the related social order, intergenerational equity may have different meanings. It should to be understood in different cultural settings. Formal models are once again questioned as to their own contextual ingredients. Without generalising the cultural relativity of models, intergenerational, as a particular form of procedural justice, needs to be analysed with respect to cultural diversity. That does in no way mean a rejection of any attempt to understand climate change in building formal models. Rather it means seriously limiting their relevance for policy recommendations on a world wide scale.

\section{Asset management facing ethics}

The application of these different aspects of equity within the operational context of business is complex. One of the main reasons is given as the simple fact that macroeconomic growth objectives are not necessarily in the scope of businesses. Moreover, if models of economic growth are extended to environmental issues, equity problems occur because of the related change in relative prices designing winners and losers of the consequences of this change. The theory of welfare has extensively discussed the compensation criteria, no one can be considered as being scientifically neutral and value-free. The business has no clear guidance in order to know what society is considering as just. It can only deduce from the following attempts to translate ethical principles into operational concepts.

The first one is Agenda 21 that gives a concrete content to the ethical dimension of sustainable development. As a cost-benefit analysis for evaluating economic decisions and their consequences for the environment always leads to multi-criteria determination in order to properly carry out the required impact assessment, the weighting of the criteria is crucial for the outcome. This weighting should be the result of a participatory process of all stakeholders, who are concerned by an economic decision in a concrete and therefore mostly local context. Businesses cannot ignore this evolution and are bound to collaborate more and more with local groups.

The second is the strict application of the BAT principle, namely to produce and to distribute goods and services according to the best available technique in respect to the environment. Those businesses that are technologically advanced from an environmental point of view have a strategic advantage over their competitors reflected in the appreciation of the stock market.

The third way to translate ethical principles into concrete action follows logically from the two preceding ones. Participation and stock market evaluation is at the root of green asset management and of numerous evaluation procedures in order to determine how the business handles its relationship with the stakeholders from the civil society and how to determine green investment. Table 2 lists some examples of such an endeavour. 
These different attempts to evaluate business practices in order to promote the social and ecological responsibility of the business are the precondition for creating portfolios for green and social asset management.

However, the success of that kind of assessment management may be more mundane. The performance of such portfolios is as good as and sometimes better than ordinary portfolios. Table 3 compares the performance of a "green portfolio" composed of only shares of the members of the World Business Council of Sustainable Development to the usual benchmarks in the US and in Europe at the end of August 2005.

Table 2: $\quad$ Examples of norms and standards of evaluation.

\begin{tabular}{|l|l|}
\hline Organisation & Main objectives \\
\hline Global reporting & $\begin{array}{l}\text { Global Reporting Initiative, Sustainability Reporting } \\
\text { Guidelines on Economic, Environmental and Social } \\
\text { Performances }\end{array}$ \\
\hline Accountability & $\begin{array}{l}\text { Promotion of standard AA 1000 for Governance (applied } \\
\text { by Novo Nordisk, The Body Shop, British Telecom e.g.) } \\
\text { Institute of Social and Ethical Accountability }\end{array}$ \\
\hline ISO & $\begin{array}{l}\text { Promotion of norm ISO 1431 by the International } \\
\text { Organisation for Standardisation Council on Economic } \\
\text { Priority Accreditation Agency }\end{array}$ \\
\hline CEPAA & $\begin{array}{l}\text { Promotion of a Social Accountability standard ISP 8000 } \\
\text { Guide for businesses Council for Sustainable Development }\end{array}$ \\
\hline WBCSD & \\
\hline
\end{tabular}

Table 3: $\quad$ Performance.

\begin{tabular}{|l|l|l|}
\hline Market & 1 Year & 5 Years \\
\hline Standard \& Poor's 500 & $12.5 \%$ & $-16.4 \%$ \\
\hline "green" portfolio & $10.8 \%$ & $14.1 \%$ \\
\hline Dow Jones Europe & & \\
\hline Stoxx 50 & $1.4 \%$ & $-29.1 \%$ \\
\hline "green" portfolio & $5.1 \%$ & $17.9 \%$ \\
\hline
\end{tabular}

Source: Dexia and BCSD.

These figures illustrate that, with the exception of a one year performance in the US (Standard \& Poor's 500), the comparisons are in favor of the "green" portfolios.

\section{Conclusion}

The tendency towards corporate governance, social norms and indicators for sustainable development will also increase in the future for two reasons. The first is internal, the second external to the business. 
The internal reason is linked to the motivational behaviour of employees. In order to increase the motivation to work, the business has to send out a clear message to its own employees, that it cares for the environment and that it is concerned by social issues.

The external reason is linked to the behaviour of consumers. The legitimacy of a business is crucial for a convincing marketing. The increasing awareness for environmental and social concern is therefore shaping business behaviour and its evaluation by the stock market.

Are new business ethics necessary or is it enough to strengthen the wellknown ethical principles of the market? It is difficult to answer this question and to guess future trends, but the traditional economic rationality will be completed more and more by the precautionary principle, competition by local cooperation, mobility by social rooting and finally the implicit social contract within generations will be extended to intergenerational responsibility. Modern economic teaching should fully integrate these aspects right from the beginning.

\section{References}

[1] Constanza, R., Ecological Economics: The Science and Management of Sustainability, Columbia University Press: New York, 1991.

[2] Dore, M.H.I. \& Mount, T.D. (eds). Global Environmental Economics, Equity and the Limits to Markets, Blackwell: Oxford, 1999.

[3] Feldmann, A.M., Welfare Economics and Social Choice Theory, Kluwer: Boston, 1983.

[4] Harsanyi, J. (1955), Cardinal welfare, Individualistic ethics, and interpersonal comparisons of utility. Journal of Political Economy, No 63, 1955.

[5] Hausman, D.M. \& McPerson, M.S., Taking ethics seriously: Economics and contemporary moral philosophy. Journal of Political Economy, No 63, 1993.

[6] Martinez-Allier, J., Ecological Economics, Blackwell: Oxford, 1987.

[7] O'Connor, M. \& Spash, C.L., Valuation and the Environment, Theory, Method and Practice, Edward Elgar: Aldershot and Brookfield, 1999.

[8] Sen, A., On Economic Inequality, Oxford University Press: Oxford, 1973, expanded edition with a substantial annexe by J. E. Foster and A. Sen, 1997.

[9] Simon, H.A., Models of Bounded Rationality, The MIT Press: Cambridge and Massachusetts, 1982.

[10] Söderbaum, P., Ecological Economics, Earthcan: London, 2000.

[11] Tietenberg, T.H., Innovation in Environmental Policy, Economic and Legal Aspects of Recent Developments in Environmental Enforcement and Liability, Edward Elgar: Aldershot and Brookfield, 1992.

[12] World Commission on Environment and Development, Our Common Future, Oxford University Press: Oxford and New York, 1987. 